\title{
Importance of Furosemide in Pet-Ct for SBRT Planning in Persistent Cervicouterine Cancer
}

\author{
*Jasmina Alexander \\ Panama University, Panamá, República of Panama, Florida, USA
}

Submission: May 26, 2017; Published: June 19, 2017

"Correspondence Address: Jasmina Alexander, Panamá, República of Panama, Florida, USA, Email: JIALEXA@GMAIL.COM

Abstract

Although 18F-FDG is now a days the universal tracer in PET for oncology, it is a marker of metabolic activity that is not specific enough to give positive results in a variety of benign physiological and pathological conditions. Not all cancer pathologies are detected by PET, which should be taken into account at the time of interpretation. In the case presented below, with the use of intravenous furosemide, it was possible to reduce the artifacts caused by the physiological excretion of FDG-F18 by the renal system, which allowed to identify one of the lesions that was close to the left ureter And that it was not informed in the previous CT study, for which the PET-CT was prescribed for confirmation of the diagnosis and planning of the SBRT.

\section{Background}

A 49-year-old Female patient, $62 \mathrm{~kg}$ in weight, $1.60 \mathrm{~m}$ in height, an independent lawyer, divorced, a son. Diagnosed histologically with epidermoid carcinoma and clinically with cervical uterine cancer $(\mathrm{CaCu})$ with stage and clinical stage IB. She was submitted to a hysterectomy in 2015. She received radiotherapy for curative purposes (45 Gy to the pelvic area) from March to April 2016. In January 2017, the patient referred pain at the lower back and left leg for which an abdominal-pelvic CT, Showing a mass of $4.8 \mathrm{~cm}$ attached to the stump surrounding the left ureter and a para-aortic ganglion whose biopsy was positive for carcinoma.

\section{Indication}

Sincé the patient was already irradiated in the pelvic area, the radiotherapist, requested a simple study of PET-CT with 18F-FDG in order to establish a new treatment plan. The investigated nuclear doctor, after evaluating the case, requested injection of furosemide posterior to the whole body scanner for the accomplishment of a second pelvic scanner 30 minutes after the injection, for a better evaluation and identificación of recurrence of the illness [1].

PET-CT or Positron Emission Tomography with Computed Tomography is an imaging study of Nuclear Medicine, which is a sub specialty in the field of Radiology, in which very small amounts of radioactive material are used to diagnose And determine the severity, or to treat, a variety of diseases (various cancers, heart, gastrointestinal, endocrine, neurological disorders, and other abnormalities within the body) [2]. The CT part gives us the anatomical information, while the PET part gives us the metabolic information. The fusion of both images allows us to obtain the diagnoses by PET-CT images.

\section{Pharmacological Background}

Oral Route - Clexane, IV- Enanthyum and Vitamin C

3.1.1Pet-Ct Study Patient Preparation: It is necessary to prepare the body to optimize the uptake of the radiopharmaceutical [3].

3.1.2 Before the study: The day before the study the patient took a low carbohydrate diet (she did not consume sweets, potatoes, flour, rice, yucca, bread, gum, cough syrups, vitamins, sugary drinks and coffee). He was told he could eat protein in the form of beef, fish, chicken, legumes are also allowed. He did not make any physical effort or exercise 24 hours before the study. The day of study had 12 hours of fasting (minimum 6 hours of fasting is required for the same, except in children under 6 years, fasting in that case will be 3 hours). Drank only water (not flavored) on the day of the test, as directed. He took his usual medications 12 hours before the study (clexane and enantyum). The day of the study the patient was told to dress in comfortable clothes without metal accessories, but a disposable 
gown is provided for the study. On the day of the appointment, the patient is advised to speak as little as possible. The patient is presented 60 minutes before the scheduled time for injection, as indicated.

\section{Procedure for the pet-ct study}

Once the last indications referring to the study are given, the informed consent is signed and then the patient is channelized. In the injection room, the required data are entered into the Intego automatic injection system (name, ID card, injection site, technician, and dose) and precede with the administration of 8 the $18 \mathrm{~F}-\mathrm{FDG}$. I give one liter with water to the patient to drink it during the time of rest ( 45 minutes). The table for simulation of radiotherapy and radio surgery is placed on the table of the PETCT equipment and the patient is positioned with the arms up and the accessories that will be used for the treatment planning and the reproducibility of the position for the same (Figure 1 ). A WB (Whole Body) scan is performed first from the vertex to $1 / 3$ amid thighs. Once the WB scan is completed, the furosemide is injected into the patient to perform the pelvic complement, 30 minutes after the injection; in such a way that the possibility of false hyper metabolic adenopathies in the urinary tract can be eliminated and be more certain of an accurate diagnosis [4].

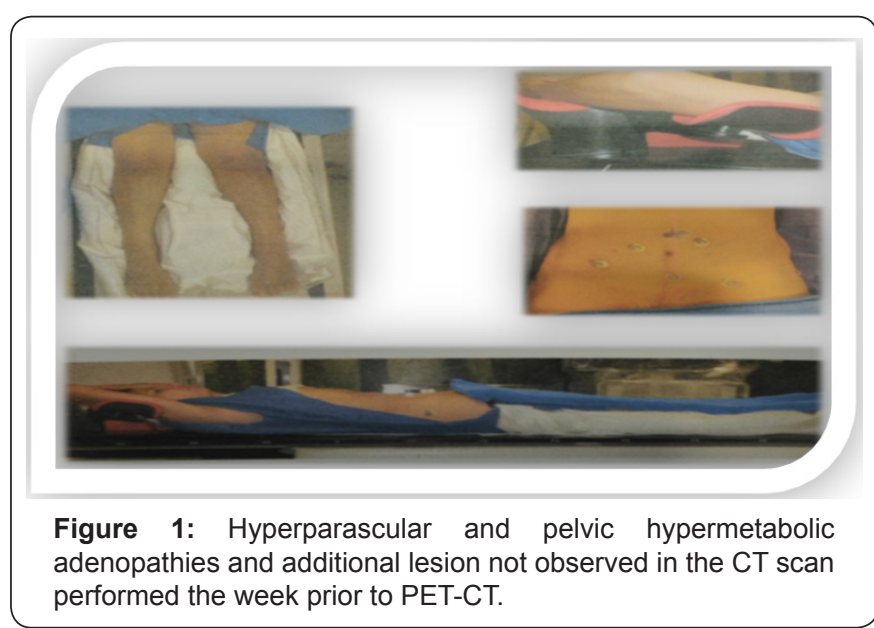

\section{Finding}

Hyperparascular and pelvic hyper metabolic adenopathies and additional lesion not observed in the CT scan performed the week prior to PET-CT.

\section{Planning}

The acquired images are used for the planning of SBRT stereotactic body radiotherapy. We used Dynamic Arcs technique (2 DArc for par aortic lesion with a dose of 32.5 Gy in 5 sessions and 2 DArc for pelvic lesions with a dose of 25 Gy in 5 sessions [5] (Figure 2).

\section{Result}

After treatment in March 2017, the patient returns to a control PET-CT on May 4, with a complete metabolic response of the left and partial Para-aortic lymph nodes of the pelvic lymph nodes (Figures $3 \& 4$ ).
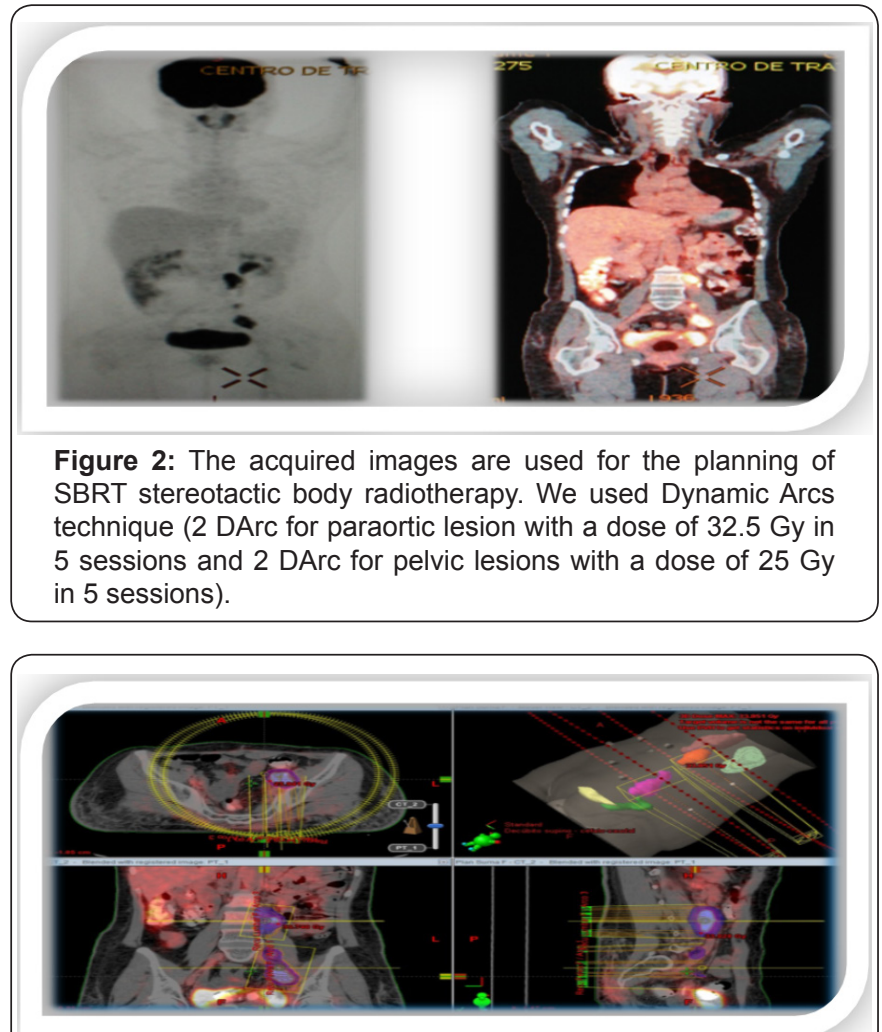

Figure 3: After treatment in March (2017), the patient returns to a control PET-CT on May 4, with a complete metabolic response of the left and partial para-aortic lymph nodes of the pelvic lymph nodes.

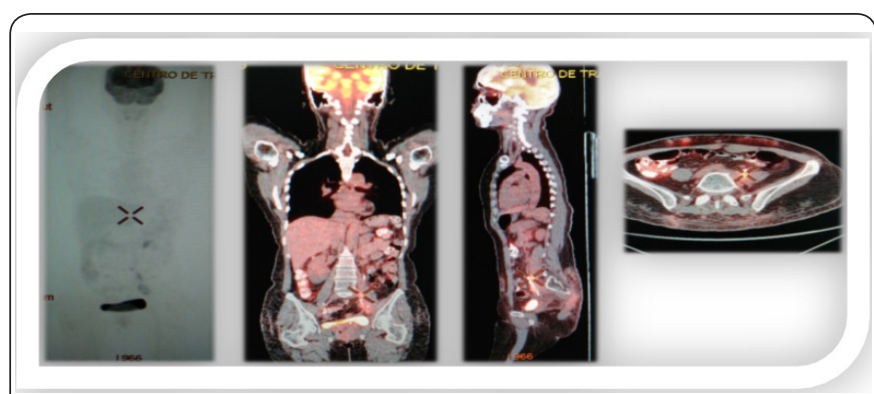

Figure 4: The use of intravenous furosemide is of great importance in cancers in which the excretory system or part of it is suspected or already has evidence.

\section{Conclusion}

The use of intravenous furosemide is of great importance in cancers in which the excretory system or part of it is suspected or already has evidence. PET-CT, as a tool in the diagnosis, staging and planning of radio surgery or stereotactic radiotherapy, has become very useful to guarantee the accuracy in the approach of cancer patients both from a diagnostic and treatment point of view.

\section{Acknowledgement}

Dr. Ya riela Herrera, Nuclear Medicine Spetialist: Dr. Eliecer Chérigo, Radiooncologist: Mtra. Eladio Abrego and Mtra. Benjamín Jaén, Medical Physicists 


\section{References}

1. Sopena R, Marti Bonmati L (2009) Técnicas de imagen multimodalidad. Todo Hospital 255: 190-196.

2. Varrone A, Asenbaum S, Vander Borght T, Kapucu, Booji J, et al. (2009) EANM procedure guidelines for PET brain imaging using [18F] FDG, version 2. OL Med Mol Imaging 36(12): 2103-2110.

3. LF Colmenter Román (2011) PET-CT en Oncologia, AMOLCA, Brasil.
4. Young H, Baum R (1999) Cremerius U Measurement of clinical and subclinical tumour response using [18F]-fluorodeoxyglucose and positron emission tomography: review EORTC recommendations. European Journal of Cancer 35(13): 1773-1782.

5. Charron M, Beyer T, Bohnen NN, Kinahan PE (2000) Image analysis in patients with cancer studied with a combined PET and CT scanner. ClinNuclMed 25(11): 905-910.

Your next submission with Juniper Publishers will reach you the below assets

- Quality Editorial service

- Swift Peer Review

- Reprints availability

- E-prints Service

- Manuscript Podcast for convenient understanding

- Global attainment for your research

- Manuscript accessibility in different formats

( Pdf, E-pub, Full Text, Audio)

- Unceasing customer service

Track the below URL for one-step submission https://juniperpublishers.com/online-submission.php 